\title{
Role of Mammography and Ultrasound in the Evaluation of Palpable Breast Masses with Histopathological Correlation
}

\author{
Sudhakar Kanumuri ${ }^{1}$, Kada Venkata Ramana ${ }^{2}$, Sudhir Sachar ${ }^{3}$ \\ ${ }^{1}$ III Year Postgraduate, ${ }^{2}$ Associate Professor, Department of Radiology, Konaseema Institute of Medical Science, Amalapuram, \\ Andhra Pradesh, ${ }^{3}$ Professor and HOD, Department of Radiodiagnosis, Konaseema Institute of Medical Sciences and Research \\ Foundation, Amalapuram, A.P., India
}

Corresponding author: Dr. Kada Venkata Ramana Associate Professor, Department of Radiology, Konaseema Institute of Medical Science, Amalapuram, Andhra Pradesh, India

DOI: http://dx.doi.org/10.21276/ijcmsr.2019.4.2.4

How to cite this article: Sudhakar Kanumuri, Kada Venkata Ramana, Sudhir Sachar. Role of mammography and ultrasound in the evaluation of palpable breast masses with histopathological correlation. International Journal of Contemporary Medicine Surgery and Radiology. 2019;4(2):B16-B20.

\section{A B S T R A C T}

Introduction: Breast cancer is most common cause of cancer death in women and overall fifth common cause of cancer deaths in the world. ${ }^{1}$ In India, breast cancer is the second most common cancer in women, next to cervical cancer. Early detection of breast cancer reduces the morbidity and mortality rate. Present study was designed to evaluate the role of mammography and sonography independently and combinedly in diagnosing palpable breast mass lesions with histopathological correlation.

Material and Methods: 50 patients aged 30 and above with palpable abnormalities of breast underwent combined mammographic and sonographic evaluation.

Results: In this study 52 breast masses from 50 patients were evaluated with USG and Mammography and the incidence of malignancy was 22\%. 10 cases were diagnosed as malignant after a combined mammographic and sonographic evaluation and only one case was missed. 33 of the 50 cases were categorized as benign after a combined mammographic and sonographic evaluation, only one fibrocystic case not detected on mammogram and ultrasound was diagnosed with HPE. The combined evaluation have sensitivity $95.7 \%$ and specificity is $102 \%$. The positive predictive value of this test is $100 \%$ and negative predictive value $60 \%$. This data clearly shows the value of imaging in avoiding unnecessary biopsies.

Conclusion: we can conclude that combined sonography and mammography can appropriately characterize the breast lesion and unnecessary intervention can be avoided.

Keywords: Breast Mass; Mammography; Palpable Lumps; Sonography; Biopsy.

\section{INTRODUCTION}

Breast cancer is most common cause of cancer death in women and overall fifth common cause of cancer deaths in the world..$^{1}$ In India, breast cancer is the second most common cancer in women, next to cervical cancer. Early detection of breast cancer reduces the morbidity and mortality rate. Triple assessment of breast mass include clinical examination, imaging and FNAC are the establish management protocol of palpable mass. ${ }^{2}$

Mammography is the widely accepted modality used for breast cancer screening in clinically suspected lesion. ${ }^{3}$ The adjunctive modality to mammography is high resolution Ultra Sonography (USG) which helps in characterizing a mammographically undetected palpable breast abnormality especially in dense breast. Imaging can provide definitive diagnosis, but for confirmation of diagnosis histopathology and cytology is essential. The present study was designed to compare the accuracy of Mammography and ultrasonography in the evaluation of palpable breast masses with histopathololgical correlation.

\section{MATERIAL AND METHODS}

In present prospective study we have included fifty patients above 30yrs of age who has palpable mass in breast and underwent mammography and USG in the department of Radio-diagnosis, KIMS and RF, Amalapuram during November 2017 to October 2018. All patients underwent diagnostic mammography, which included cranio-caudal and medio-lateral oblique views. Later all the patients were subjected to sonography of breast.

Mammography was performed by using Allengers Mammography Venus Adv model equipment in two views(i.e., cranio-caudal and medio-lateral oblique views) are used and other views and high $\mathrm{kVp}$ and low $\mathrm{mAs}$ exposures vary with the thickness of the breasts with minimum $\mathrm{kVp}$ 23.0 to $\max \mathrm{kVp} 26.0$.

Ultrasonography was performed by using Philips Ultrasound clear vue 650, using High frequency $4-12 \mathrm{MHz}$ probe and Philips clear vue $350 \mathrm{using}$ high frequency 4- $12 \mathrm{MHz}$ probe. Evaluation of radiographic characteristics of mass was carried out using BI-RADS criteria and nature of mass was 
evaluated with USG and Mammography assessment.

Ultrasound machine with colour Doppler was used to determine the following sonographic findings under the following headings:

Location-Superior / inferior / medial / lateral quadrant,

Margins - Regular / Irregular,

Width /A.P diameter ratio: $>1.4 /<1.4$,

Echotexture: Homogeneous / Heterogeneous,

Echogenicity: Hyperechoic/ Hypoechoic, Mixed echogenic / Anechoic,

Posterior sound transmission: Enhancement / shadowing, Calcification, Pseudocapsule, Vascularity and Axillary Lymphadenopathy

We used mammography to determine location, appearance, Margins, density, architectural distortion and lymphadenopathy. Result was coordinated with history and physical examination of the patients. All the finding which arouses suspicion about the lesion and possibility of malignancy were evaluated.

\section{Inclusion criteria}

All women who were suspected to have palpable breast mass

\begin{tabular}{|l|l|c|}
\hline S No & Pathology & Number of patients(\%) \\
\hline 1 & Fibroadenomas & $16(32)$ \\
\hline 2 & Simple Cyst & $5(10)$ \\
\hline 3 & Galactocele & $2(4)$ \\
\hline 4 & Duct Ectasia & $2(4)$ \\
\hline 5 & Breast Abscess & $1(2)$ \\
\hline 6 & Fat necrosis & $1(2)$ \\
\hline 7 & Fibrocystic disease & $8(16)$ \\
\hline 8 & Breast malignancy & $11(22)$ \\
\hline \multicolumn{2}{|c|}{ Table-1: Distribution of breast pathologies: } \\
\hline
\end{tabular}

either on self-examination or on clinician examination and evaluated with Mammography and Ultrasonography of the breast with subsequent biopsy/FNAC were included.

\section{Exclusion criteria}

Pregnant women 2. Women with breast implants 3. Patients already undergone surgery or received radiotherapy.

\section{STATISTICAL ANALYSIS}

All the statistical analysis were done with IBM SPSS statistical software package (version 20.0, SPSS Inc., Chicago, IL, USA). Descriptive data was presented in the form of mean $+/$ - standard deviation for continuous variables and as percentages for categorical variables. The sensitivity, specificity, positive predictive value and negative predictive value for the detection of breast lesions by mammography and ultrasonography of the breast were calculated. Chisquare test was used to compare the sensitivity and specificity of mammography and ultrasonography of the breast in the evaluation of breast lesions. $P$ value less than 0.05 was considered to indicate statistical significance.

\section{RESULTS}

In this study total 50 patients complaining of breast mass in one or both breasts were examined clinically and evaluated with USG and Mammography. The lesions were confirmed on histopathology (FNAC/biopsy/tissue from post-operative specimens).

The palpable breast masses were reported in the right breast in 22 patients, in the left breast in 26 patients and bilateral in the remaining 2 patients. Patients in this study ranged in age from 31 to 75 yrs. Majority of patients were in the age group of 30-39 yrs.

As per table 1 in 45 of the 50 cases, imaging evaluation resulted in a recommendation for surgical consultation based on a

\begin{tabular}{|c|c|c|c|c|}
\hline \multirow[t]{2}{*}{ BI-RADS categories } & \multirow[t]{2}{*}{ Total $(n=50)$} & \multicolumn{3}{|c|}{ Histopathologydiagnosis(n=47) } \\
\hline & & Benign & Malignant & Normal \\
\hline Category 0 & 1 & 0 & 0 & 1 \\
\hline Category 1: Negative & 5 & 1 & 1 & - \\
\hline Category 2: Benign & 33 & 33 & 0 & - \\
\hline Category 3: Probably benign & 1 & 1 & 0 & - \\
\hline Category 4: Suspicious & 2 & 0 & 2 & - \\
\hline Category 5:Highly suggestive of malignancy & 8 & 0 & 8 & - \\
\hline Category 6: Known biopsy-proven malignancy & - & - & - & - \\
\hline
\end{tabular}

\begin{tabular}{|l|c|c|c|}
\hline HPE diagnosis (n) & Mammography Alone & USG Alone & Combined(Mam raphy+USG) mog \\
\hline Fibroadenomas(16) & 13 & 10 & 16 \\
\hline Simple Cyst (5) & 2 & 5 & 2 \\
\hline Galactocele(2) & 2 & 2 & 2 \\
\hline Duct Ectasia (2) & Inconclusive in 2 cases & 2 & 1 \\
\hline Breast Abscess (1) & inconclusive & 1 & 1 \\
\hline Fat necrosis(1) & 1 & 7 & 7 \\
\hline Fibrocystic disease(8) & 6 & 6 & 10 \\
\hline Breast malignancy (11) & 8 & Inconclusive & Inconclusive \\
\hline Normal glandular tissue(1) & \multicolumn{2}{|c|}{ inconclusive } & \\
\hline \multicolumn{2}{|r|}{} \\
\hline
\end{tabular}




\begin{tabular}{|l|c|c|c|c|c|}
\hline Modality & Sensitivity & Specificity & Positive Predictive value & Negative P redictive & Accuracy \\
\hline Mammography & $68.0 \%$ & $100.0 \%$ & $100.0 \%$ & $16.6 \%$ & $70 \%$ \\
\hline USG & $70.2 \%$ & $100.0 \%$ & $100.0 \%$ & $17.6 \%$ & $72 \%$ \\
\hline Mammography+USG & $95.7 \%$ & $100.0 \%$ & $100.0 \%$ & $60.0 \%$ & $96 \%$ \\
\hline \multicolumn{6}{|l}{ Table-4: Diagnostic accuracy of Mammography, USG and USG + Mammography } \\
\hline
\end{tabular}
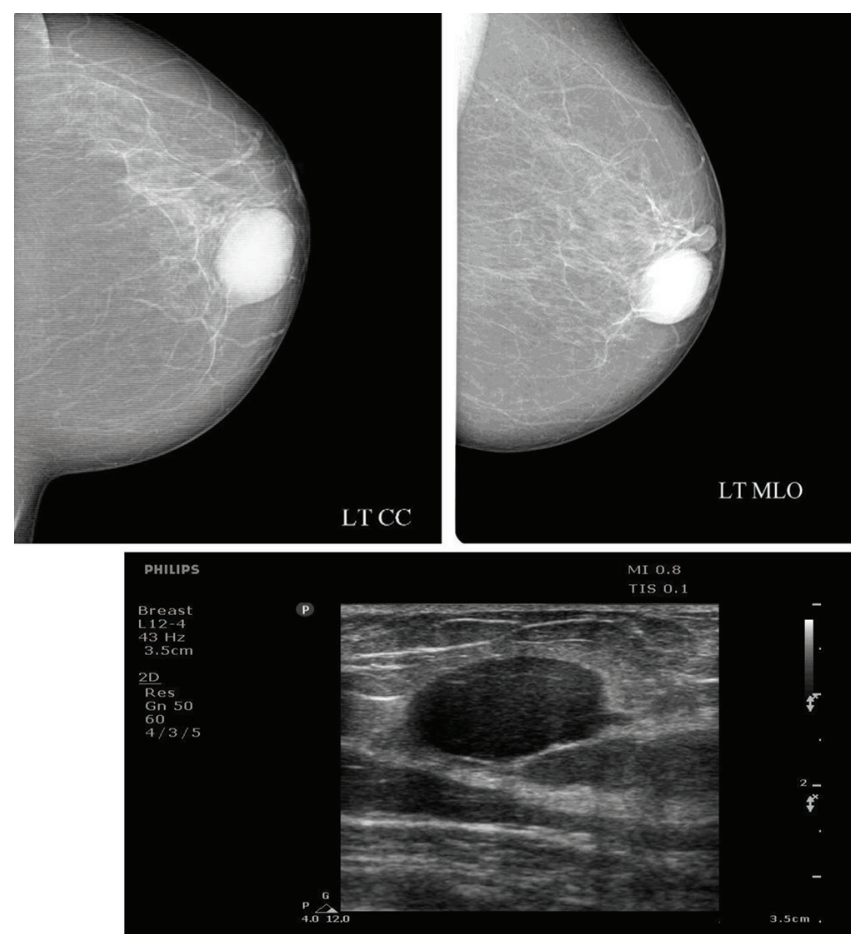

Case-1: Fibroadenoma
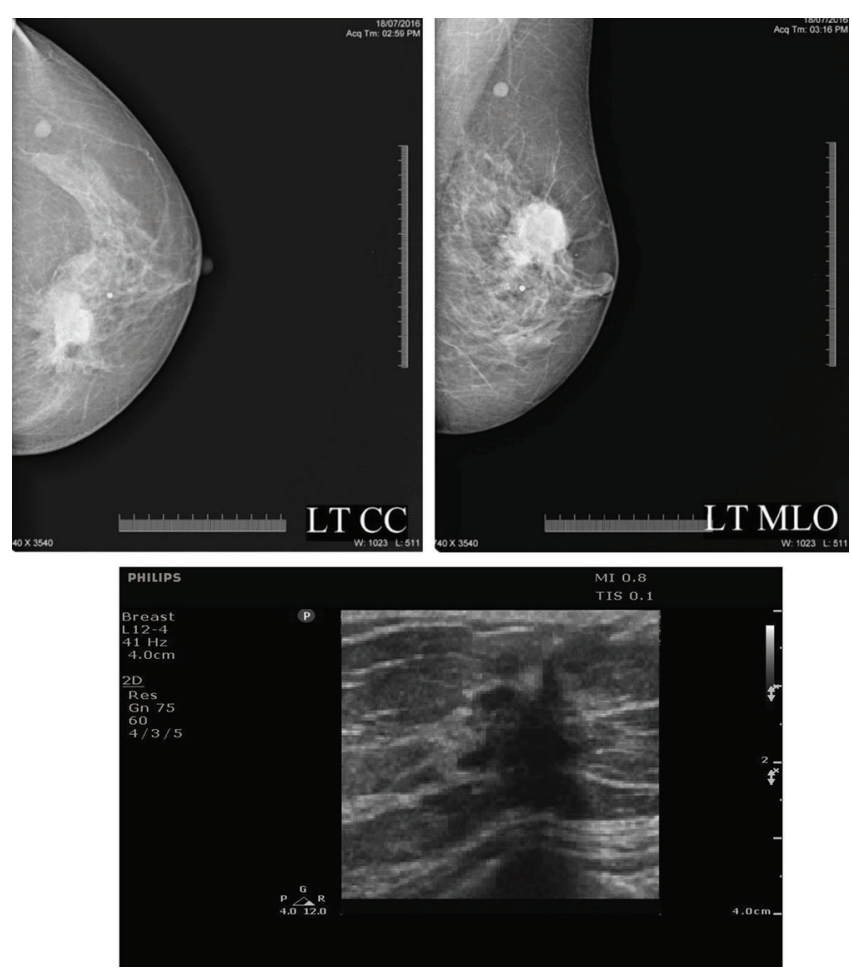

Case-2: Invasive Ductal Carcinoma

combination of mammographic and sonographic features. Two more patients were also recommended for surgical consultation despite negative imaging findings because of
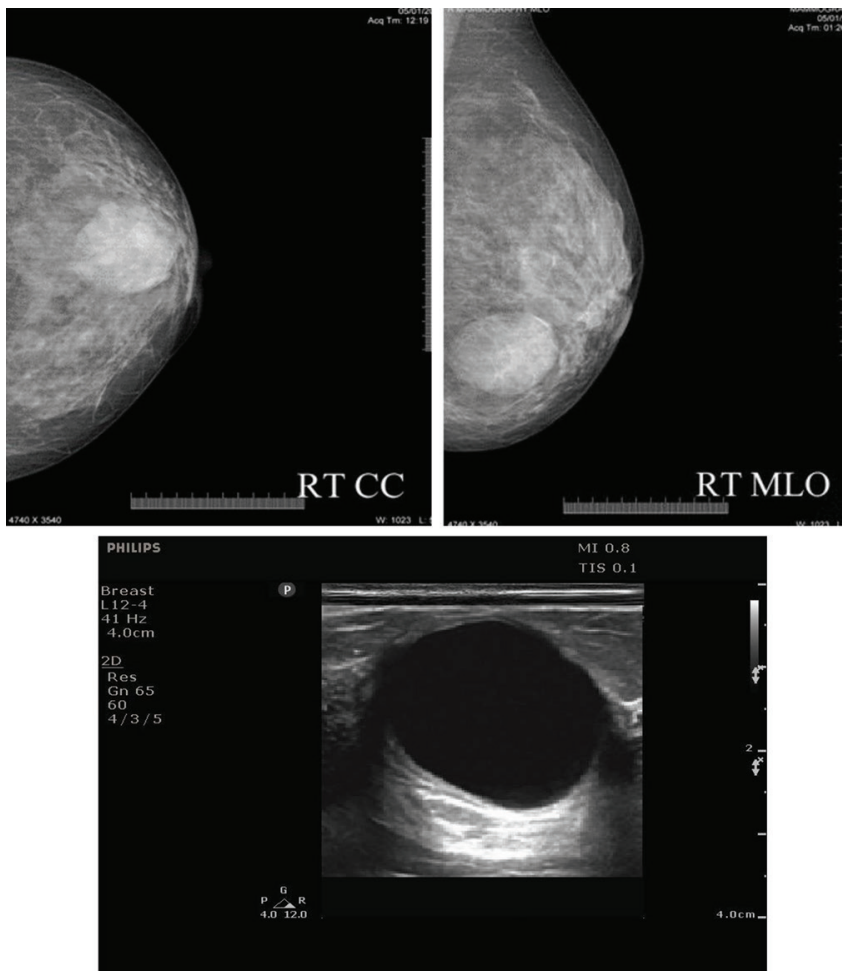

Case-3: Simple Cyst

high degree of clinical suspicion. All of these underwent biopsy (biopsy/tissue from post-operative specimens/ aspiration).Of these 47 patients 11 were malignant and remaining were as described in table-1. Among 2 patients with negative imaging findings one had histological diagnosis of fibrocystic disease and another had malignancy.

There were 5 cases of cysts, which was clearly detected by USG, but Mammography picked up only 2. Out of the 8 fibrocystic cases, Mammography alone picked 6 whereas the USG missed only 1 case. Among 2 cases of galactocele Mammography findings were inconclusive, whereas the USG correctly detected both cases. Out of 16 cases of fibroadenoma, Mammography detected 13 and USG detected 10. By the combined USG and Mammography approach all 16 cases were correctly diagnosed.

The HPE reports revealed 11 patients with a carcinoma. Out of 11 malignancies USG alone detected only 6, Mammography alone picked 8 and when combined picked up 2 more cases but none picked up one case that was identified with HPE alone done in view of high clinical suspicion (table-3).

Sensitivity, specificity were derived for USG and Mammography individually and also combined. Overall, the histopathological results when correlated with each modality findings, revealed that Mammography had a sensitivity of $68.0 \%$ and USG 70.2\% when used alone in detecting these lesions of the breast compared to a sensitivity of $95.7 \%$ obtained by their combined approach (table-4). 
In this study there was no significant difference in sensitivity between mammography and USG in detecting breast disease $(p=0.98)$. But there was a significant difference when mammography and Ultrasonography were done independently compared to combination of mammography and USG ( $\mathrm{p}=0.022)$.

A histopathologically diagnosed case of Fibroadenoma in a $40 \mathrm{yr}$ old patient came with palpable mass in the left breast, mammography $1 \mathrm{~A}) \mathrm{CC}$ and $1 \mathrm{~B}) \mathrm{MLO}$ views shows scattered fibroglandular dense breast with a high density oval shaped mass with circumscribed margins in medial quadrant, correspondingultrasound1C) image shows oval shaped well defined hypoechoic lesion with increased vascularity, oriented parallel to skin, features suggestive of BIRADS II a benign lesion (figure-1). A histopathology proven case of Invasive Ductal Carcinoma in a $50 \mathrm{Y}$ old patient, mammography 6A) $\mathrm{CC}$ and 6B)LO views shows a fibro glandular breast predominantly fatty with a dense irregular lesion with spiculated margins in the upper outer quadrant associated with few segmental micro calcifications BIRADS $\mathrm{V}$ and ultrasound image shows an irregular hypoechoic lesion with indistinct margins with posterior acoustic shadowing, suggestive of malignant lesion (figure-2). A histopathologically diagnosed case of Simple Cyst in a 38 yr old female patient came with palpable mass and tenderness in right breast, mammography $2 \mathrm{~A}) \mathrm{CC}$ and 2B)MLO Views shows a dense fibroglandular breast with a well defined round, dense lesion in lower inner quadrant, corresponding ultrasound 2C) image shows a circumscribed, round, anechoic lesion with posterior acoustic enhancement oriented parallel to skin, suggestive of BIRADS II a benign lesion (figure-3).

\section{DISCUSSION}

Breast cancer is a common malignancy in developing world and consciousness about it is essential for early detection and cure.

The gold standard for evaluation for breast cancer is mammography ${ }^{4}$ when it is combined with USG the sensitivity rate used to become high. ${ }^{5}$ It has been reported that only $4 \%$ of palpable breast lesion are malignant. ${ }^{7,8}$ Mammography can establish the benign cause of palpable lesion and avoid further investigation. But false negativity in case of mammography was represent to be $16.5 \% .^{9}$ When it is used with USG the false negativity rate used to reduce to 0 to $2.6 \%{ }^{10,11}$

In present study $66 \%$ patients with palpable breast mass were begin, 20\% patients have malignant feature, $4 \%$ patient are clinically suspicious but have negative imaging study. They went for biopsy and out of that 11 were management and 1 were found to be benign.

Morris KT et al has stated that Triple test that is physical examination, radiography and pathology have diagnostic accuracy of $100 \% .^{12,13}$ We have observed that out of 50 patients 33 were benign lesions. Out of that 13 were benign solid and 20 were cystic, 16 cases were fibro adenoma. In our study combined mammography and USG are more sensitive in diagnosis fibro adenoma This finding is supported by the work of Lister D et al and Moss et al. ${ }^{14,15}$
Kolb Tm et al in 1998 has also found that combining USG as additional major with mammography increases the cancer detection rate. ${ }^{16}$

We have observed that sensitivity and specificity of combined approach was $95.7 \%$ and $100 \%$ respectively. The positive predictive value was $100 \%$ and the negative predictive value was $60 \%$ with palpable breast mass. Observation of various author are tabled below.

\begin{tabular}{|l|c|c|}
\hline & Sensitivity & Specificity \\
\hline Moss et al (12) & $94.2 \%$ & $67.9 \%$ \\
\hline Shefty pk et al (17) & $100 \%$ & $80.1 \%$ \\
\hline Barlow et al (18) & $88 \%$ & $22 \%$ \\
\hline
\end{tabular}

These finding support our study.

\section{CONCLUSION}

Combined mammography and sonography approach plays an important role in the management of palpable breast lesions. They aid in Characterization of the palpable breast lesions.Avoids unnecessary interventions in which imaging findings are unequivocally benign. Negative findings on combined mammographic and sonographic imaging have very high specificity and are reassuring to the patient.

\section{REFERENCES}

1. World Health Organization, - Fact Sheet No. 297: Cancer, II 2006.

2. Cavert MM, O"Donnell ME, Aroori S, Badger SA, Sharif MA, Crothers JG et al. Ultrasound is a useful adjunct to mammography in the assessment of breast tumours in all patients. Int J ClinPract, 2009;63 (11):1589-94.

3. Barton MB, Elmore JG, Fletcher SW. Breast symptoms among women enrolled in a health maintenance organization: frequency, evaluation, and outcome. Ann Intern Med 1999;130(2):651-679.

4. Prasad SN, Houserkova D, A comparison of mammography and ultrasonography in the evaluation of breast masses. Biomed Pap Med Fac Univ Palacky Olomouc Czech Repub. 2007; 151(2):315-22.

5. Prasad SN, The role of various modalities in breast imaging. Biomed Pap Med Fac Univ Palacky Olomouc Czech Repub. 2007; 151(2):209-18

6. Bennett IC, Freitas R Jr, Fentiman IS. Diagnosis of breast cancer in young women. Avst NZJ Surg 1991; 61(1):284-289.

7. Barton MB, Elmore JG, Fletcher SW. Breast symptoms among women enrolled in a health maintainaence organisation.Frequency, evaluation and outcome. Ann intern Med 1999; 130 (8):651-657.

8. Perdue P, Page D, Nellestein M, Salem C, Galbo C, Ghosh B. Early detection of breast carcinoma; a comparision of palpable and non palpable lesions: Surgery 1992;111(6):656-659.

9. Conveys EC, Geraghty JG, O 'Laoide R, Hourihane IB, O’Higgins NJ. Reasons underlying negative mammography in patients with palpable breast cancer. clin.radiology 1994: 49(2): 123-125.

10. Soo MS, Rosen EI, Baker JA, Vo TT, Boyd BA. Negative predictive value of sonography with mammography in patients with palpable breast lesions.AJR AmJ 
Roentgenol 2001;177(1); $1167-1170$.

11. Moy L, slantez PJ, Moore R et al. Specificity of mammography and US in the evaluation of a palpable abnormality 2002:225(5):176-181.

12. Morris KT, Vetto JT, Petty JK, Lum SS, Schmidt WA, Toth-Fejel $\mathrm{S}$ and colleagues. A new score for the evaluation of palpable breast masses in women under age 40. American journal of surgery 2002; 184(3):245-7.

13. Ahmed I, Nazir R, Chaudhary MY, Kundi S, Triple assessment of breast lump. J Coll Physicians Surg Pak. 2007;17(9):535- 8

14. Lister D, Evans AJ, Burrell HC, Blamey RW, Wilson $\mathrm{AR}$, Pinder SE, and collegues. The accuracy of breast ultrasound in the evaluation of clinically benign discrete, symptomatic breast lumps. Clin Radiol 1998; 53(3):490-2.

15. Moss HA, Britton PD, Flower CDR, Freeman AH, Lomas DJ, Warren RML. How reliable is modern breast imaging in differentiating benign from malignant breast lesions in the symptomatic population? Clin Radiol 1999; 54(10):676-682.

16. Kolb TM, Lichy J, Newhouse JH. Comparison of the performance of screening mammography, physical examination, and breast US and evaluation of factors that influence them: an analysis of 27,825 patient evaluations. Radiology 2002; 225(6):165-175.

17. Shetty MK and Shah YP, Sharman RS. Prospective evaluation of value of combined mammographic and sonographic assessment in patients with palpable abnormalities of breast. J. Ultrasound Med 2003:22(5);263-268.

18. Barlow WE, Lehman CD, Zheng $Y$, et al. Performance of diagnostic mammography for women with signs or symptoms of breast cancer. J Natl Cancer Inst 2002; 94(4):1151-9.

Source of Support: Nil; Conflict of Interest: None

Submitted: 13-02-2019; Accepted: 12-03-2019; Published online: 24-04-2019 